\title{
Bilateral ocular adnexal diffuse large cell lymphoma with unilateral conjunctival involvement
}

\begin{abstract}
Orbital and periorbital diffuse large B cell lymphoma (DLBCL) presents a rapidly growing solitary nodal or extranodal tumor with an aggressive clinical course despite being high grade; they are most commonly seen unilaterally and without conjunctival involvement. We present a case of bilateral ocular adnexal DLBCL with unilateral conjunctival involvement. 86-year-old male patient presented with a two week history of unilateral ptosis and erythema of the left upper eyelid. Upon examination, a salmon colored mass at superior mid-bulbar conjunctiva hidden by the eyelid was found. Orbital magnetic resonance imaging (MRI) revealed bilateral intraconal lesions. Excisional biopsy was performed and histopathology was consistent with diffuse large B-cell lymphoma (DLCBL). Systemic work up including PET scan showed involvement of bilateral cervical lymphoid chains, abdominal para-aortic lymphatic nodes and the right lung.
\end{abstract}

Keywords: orbital lymphoma, diffuse large b cell lymphoma, intraconal
Volume 4 Issue 3 - 2016

\author{
Ali Kal,' Zeynep E Ercan,' Gülsah Tanriasiki,' \\ Egemen Çiftçi, ${ }^{2}$ Esra Zeynep Coskunoglu ${ }^{3}$ \\ 'Department of Ophthalmology, Baskent University, Turkey \\ ${ }^{2}$ Department of Radiology, Baskent University, Turkey \\ ${ }^{3}$ Department of Pathology, Baskent University, Turkey
}

Correspondence: Ali Kal, Department of Ophthalmology, Baskent University Konya Hospital, Hoca cihan Mah, Saray Caddesi no.I Selçuklu Konya/Turkey, Tel 542246I347, Emaildralikal@yahoo.com

Received: April 18, 2016 | Published: May 09, 2016
Abbreviations: DLBCL, diffuse large b cell lymphoma; MRI, magnetic resonance imaging

\section{Introduction}

Ocular adnexal lymphomas (OAL) represent malignant lymphoid neoplasms which develop as primary or secondary tumor manifestations in the orbit, the conjunctiva, and eyelid..,2 Orbital lymphomas present with painless diffuse ill-defined or circumscribed mass that may be associated with proptosis, blurred or double vision, or lid erythema. ${ }^{3}$ Unlike the most common subtype, extranodal marginal zone B-cell lymphoma, orbital and periorbital diffuse large $\mathrm{B}$ cell lymphoma (DLBCL) is an uncommon entity and presents as rapidly growing solitary nodal or extranodal tumor with an aggressive clinical course. ${ }^{1,4-6}$ We present a case of bilateral ocular adnexal DLBCL with unilateral conjunctival involvement.

\section{Case report}

An 86-year-old man presented with a two week history of unilateral ptosis and erythema of the upper eyelid (Figure 1). On examination, the best corrected visual acuity was 20/40 in both eyes. Anterior segment biomicroscopy of the left eye showed a diffuse, slightly elevated, fleshy mass at mid-bulbar conjunctiva hidden by upper eyelid and bilateral nuclear cataracts (Figure 2). The marginal reflex distance of the right eye was $5 \mathrm{~mm}$, while it was $2 \mathrm{~mm}$ on the left side. No proptosis was detected. The orbital magnetic resonance imaging (MRI) showed $18 \times 8 \times 20 \mathrm{~mm}$ lesion with unclear margins, between levator palpebra superior and superior rectus muscle in the left orbit (Figure 3). Right eye, which had no pathological findings during the examination, also had a $14 \times 8 \times 8.5 \mathrm{~mm}$ lesion located near central of the lateral rectus of the right eye (Figure 4). Excisional biopsy was performed to the conjunctival mass and sent for histopathological analysis (Figure 5). Atypic lymphocytes with diffuse infiltration and plasma cells with positive CD20, MUM-1, Bcl-2 immunohistochemistry staining and a Ki-67 labeling of 40\% were observed (Figure 6). Systemic work up including PET scan showed the involvement of bilateral cervical lymphoid chains, abdominal paraaortic lymphatic nodes and the right lung. Immediate chemotherapy was initiated, however the patient only survived for two more months after the diagnosis.

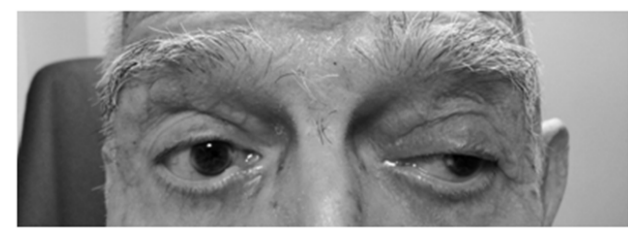

Figure I Left ptotic upper eyelid.

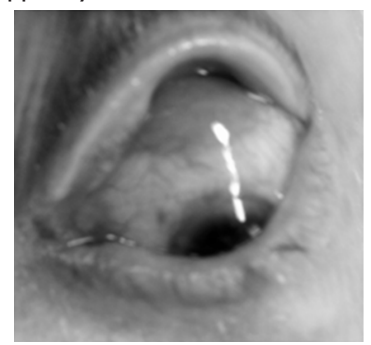

Figure 2 Elevated, fleshy mass at mid-bulbar conjunctiva.

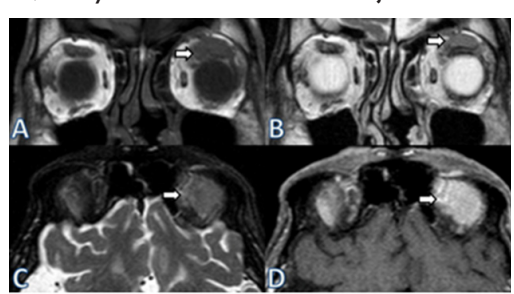

Figure 3 Left orbital MRI showing $18 \times 8 \times 20 \mathrm{~mm}$ isointense lesion with unclear margins, between levator palpebra superior and superior rectus muscle in the left intraconal space (A), minimal hyper intensity at coronal T2-weighted images (B), isointense in fat suppressed T2-weighted imaging (C), opaque lobule after IV contrast injection (D). 


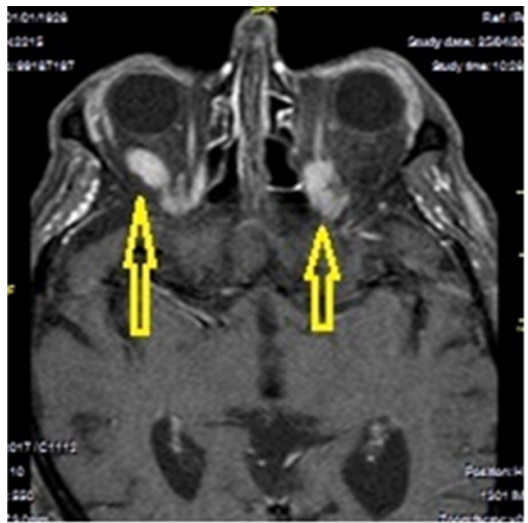

Figure 4 Orbital MRI with $14 \times 8 \times 8.5 \mathrm{~mm}$ lesion located near central of the lateral rectus of the right eye.

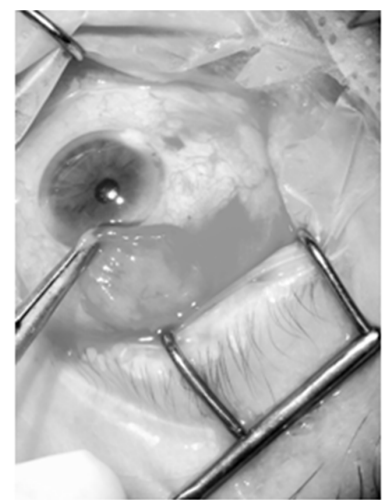

Figure 5 Excisional biopsy of left conjunctival mass.

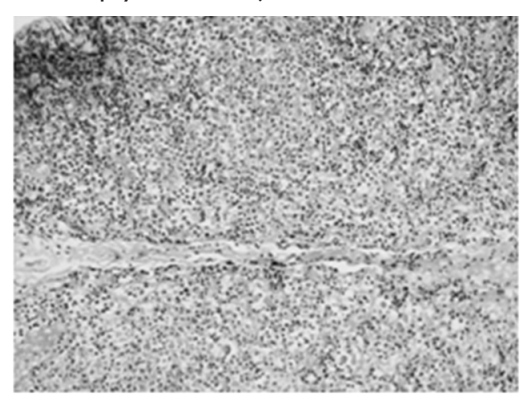

Figure 6 Infiltration of large atypical cells (200X).

\section{Discussion}

Ocular adnexal lymphoma is the most common primary orbital malignancy in adults. It occurs in roughly $5 \%$ of cases of systemic nonHodgkin lymphoma and $8 \%$ of all extranodal lymphomas. ${ }^{2,5}$ Without systemic involvement, it has a high survival rate. ${ }^{6}$ However, systemic lymphoma may be present prior to, at or in the follow up. ${ }^{7}$ In fact, Hatef et al., ${ }^{4}$ suggested that extra orbital involvement is present at diagnosis in more than half of patients presenting with OAL. Orbital DLBCL represents $7-21 \%$ of these groups..${ }^{69}$ Rasmussen et al., ${ }^{10,11}$ concluded in their study that ocular adnexal DLBCL predominantly affects elderly people and mostly presents with unilateral involvement. Primary DLBCL with involvement of the conjunctiva is rare. ${ }^{8,11}$ Priego et al., ${ }^{12}$ study in MRI imaging of OALs concluded that they typically involve the superior rectus muscle, lateral rectus muscle, lacrimal gland and eyelid. They also suggested that the involvement of intraconal space is usually associated with the extraconal one and therefore, an intraconal involvement alone will not be the main pattern of lymphoma in the orbit. While this may be true for commonly seen extranodal marginal zone B-cell lymphoma, Madge et al suggested that an intraconal mass is seen with DLBCL more commonly than other subtypes. ${ }^{6}$ Advanced age, male sex and the intraconal mass in our case corresponds to these studies. The bilaterality and the conjunctival involvement of DLBCL, on the other hand, are seen less commonly. ${ }^{8-12}$

\section{Conclusion}

DLBCL may present at any stage and might be bilateral even though presenting unilaterally and should always be considered when encountering an older adult with proptosis, eyelid erythema or diplopia.

\section{Acknowledgments}

None.

\section{Ethical consent}

None.

\section{Conflicts of interest}

The author declares there are no conflicts of interest.

\section{References}

1. Ahmed S, Shahid RK, Sison CP, et al. Orbital Lymphomas: A Clinicopathologic Study of a Rare Disease. Am J Med Sci. 2006;331(2):7983.

2. O Bairey, I Kremer, E Rakowsky, et al. Orbital and Adnexal Involvement in Systemic Non-Hodgkin's Lymphoma Cancer. 1994;73(9):2395-2399.

3. Demirci H, Shields CL, Karatza EC, et al. Orbital Lymphoproliferative Tumors: Analysis of Clinical Features and Systemic Involvement in 160 Cases. Ophthalmology. 2008;115(9):1626-1631.

4. HatefE, Roberts D, McLaughlin P, et al. Prevalence and Nature of Systemic Involvement and Stage at Initial Examination in Patients with Orbital and Ocular Adnexal Lymphoma. Arch Ophthalmol. 2007;125(12):1663-1667.

5. Jenkins C, Rose GE, Bunce C, et al. Histological Features of Ocular Adnexal Lymphoma (Real Classification) and their Association with Patient Morbidity and Survival. Br J Ophthalmol. 2000;84(8):907-913.

6. Madge SN, McCormick A, Patel I, et al. Ocular Adnexal Diffuse Large B-Cell Lymphoma: Local Disease Correlates with Better Outcomes. Eye (Lond). 2010;24(6):954-961.

7. McKelvie PA, McNab A, Francis IC, et al. Ocular Adnexal Lymphoproliferative Disease: A Series of 73 Cases. Clin Experiment Ophthalmol. 2001;29(6):387-393 .

8. Precupanu CM, Validire P, Lévy C, et al. Primary High-Grade Ocular Adnexal Lymphoma: Clinicopathological Characteristics and Prognostic Factors of a Single-Centre Series. Am J Hematol. 2010;85(5):372-375.

9. Sullivan TJ, Whitehead K, Williamson R, et al. Lymphoproliferative Disease of the Ocular Adnexa: A Clinical and Pathologic Study with Statistical Analysis of 69 Patients. Ophthal Plast Reconstr Surg. 2005;21(3):177-188.

10. Rasmussen PK. Diffuse Large B-Cell Lymphoma and Mantle Cell Lymphoma of the Ocular Adnexal Region, and Lymphoma of the Lacrimal Gland: An Investigation of Clinical and Histopathological Features. Acta Ophthalmol. 2013;5:1-27. 
11. Rasmussen PK, Ralfkiaer E, Prause JU, et al. Diffuse Large B-Cell Lymphoma of the Ocular Adnexal Region: A Nation-Based Study. Acta Ophthalmol. 2013;91(2):163-169.
12. Priego G, Majos C, Climent F, et al. Orbital Lymphoma: Imaging Features and Differential Diagnosis. Insights Imaging. 2012;3(4):337-344. 